\title{
Unilateral minimal ovarian cancer with peritoneal implant and an intraepithelial carcinoma in the contralateral fallopian tube
}

\author{
Hiroyuki Terada ${ }^{1}$, Ken-ichi Honda ${ }^{1 *}$, Tomoko Nakagawa ${ }^{1}$, Aki Takase ${ }^{2}$, Yasushi Kurihara ${ }^{1}$, \\ Tetsuji Ando ${ }^{1}$, Masashige Tendo ${ }^{3}$, Takeshi Hori ${ }^{3}$, Keiko Miyamoto ${ }^{4}$, \\ Mayumi Inaba ${ }^{5}$, Masahiko Ohsawa ${ }^{6}$
}

\begin{abstract}
${ }^{1}$ Department of Obstetrics and Gynecology, Kashiwara Municipal Hospital, Hozenji, Kashiwara, Osaka, Japan ${ }^{2}$ Department of Obstetrics and Gynecology, Osaka City University Graduate School of Medicine, Asahimachi, Abenoku, Osaka, Japan

${ }^{3}$ Department of Surgery, Kashiwara Municipal Hospital, Hozenji, Kashiwara, Osaka, Japan ${ }^{4}$ Department of Pathology, Kashiwara Municipal Hospital, Hozenji, Kashiwara, Osaka, Japan

${ }^{5}$ Department of Pathology, Kansai Medical University Medical Center, Fumizonocho, Moriguchi, Osaka, Japan

${ }^{6}$ Department of Diagnostic Pathology, Osaka City University Graduate School of Medicine, Asahimachi, Abeno-ku, Osaka, Japan
\end{abstract}

Received: 04 February 2017

Revised: 24 February 2017

Accepted: 06 March 2017

*Correspondence:

Dr. Ken-ichi Honda,

E-mail: kenhonda@med.osaka-cu.ac.jp

Copyright: () the author(s), publisher and licensee Medip Academy. This is an open-access article distributed under the terms of the Creative Commons Attribution Non-Commercial License, which permits unrestricted non-commercial use, distribution, and reproduction in any medium, provided the original work is properly cited.

\begin{abstract}
Here we present postoperative pathology of an 82-year-old woman who presented with massive ascites, and an implant-like adenocarcinoma on her intrapelvic peritoneum, which revealed a minimal $(<5 \mathrm{~mm})$ serous adenocarcinoma on her left ovary and an intraepithelial carcinoma on inner surface of her right Fallopian tube. The left ovarian serous adenocarcinoma may have originated as an intraepithelial carcinoma on contralateral Fallopian tube.
\end{abstract}

Keywords: Contralateral fallopian tube, Intraepithelial carcinoma, Ovarian serous adenocarcinoma

\section{INTRODUCTION}

Primary extraovarian peritoneal carcinoma reportedly accounts for $\sim 10 \%$ of diagnoses of ovarian cancer. ${ }^{1}$ Recently, we treated an 82-year-old woman whose ovary seemed normal during surgery despite massive ascites and two implant-like lesions on her pelvic peritoneal surface; however, postoperative pathologic examination revealed a minimal serous carcinoma $(<5 \mathrm{~mm})$ on her left ovary and an intraepithelial carcinoma in her right fallopian tube.

We consider the carcinoma cells had likely originated in the fallopian tube and transferred to her contralateral ovary, developed invasive properties, and became implanted on the retroperitoneum.

\section{CASE REPORT}

A 82-year-old woman came to our clinic because of abdominal distension. Ultrasound examination showed massive ascites, but CT revealed no mass in the abdominal organs except for a uterine myoma with calcification (Figure 1). Her serum CA125 level was 408 $\mathrm{U} / \mathrm{mL}$, and adenocarcinoma cells were detected by ascites cytology. We performed exploratory laparotomy, with bilateral adnexectomy and supravaginal hysterectomy. 
We also resected two implant-like protrusions on her left retroperitoneum (Figure 2).
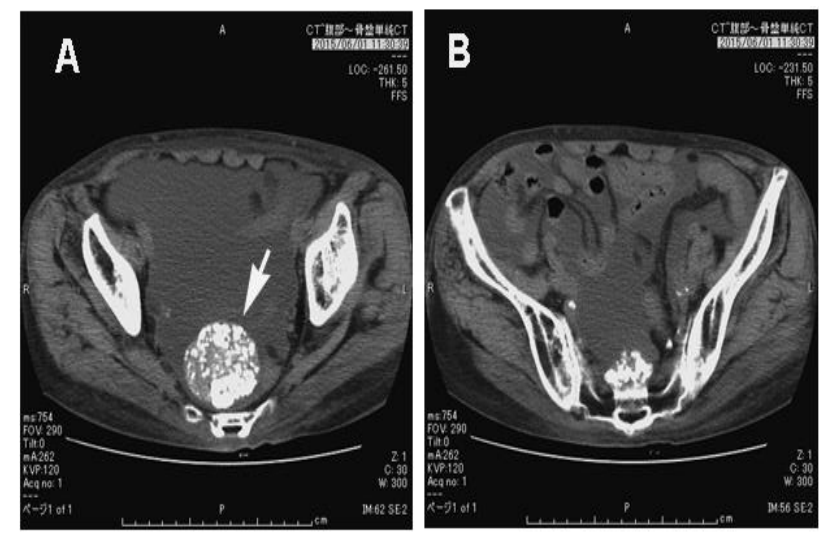

Figure 1: Preoperative pelvic CT revealed massive ascites and an uterine myoma with calcification (arrow).

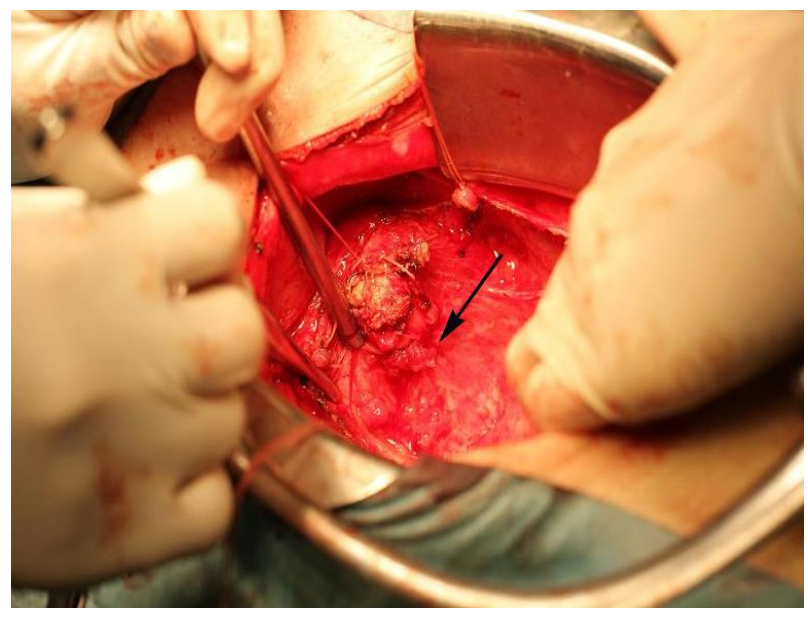

Figure 2: During surgery, two implant-like protrusions (arrow) on left side of retroperitoneum were resected.

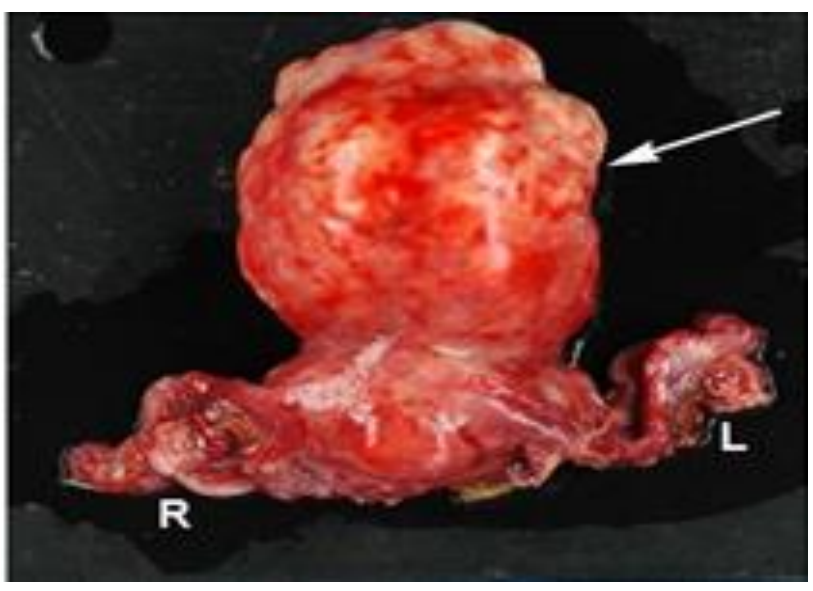

Figure 3: Operative specimens; uterine corpus with a myoma on fundus (arrow) and normal-sized adnexa (R: right adnexa; L: left adnexa).
Although, no tumor was seen macroscopically on the bilateral adnexa (Figure 3).

Microscopic examination confirmed a serous adenocaricinoma with invasion on her left ovary (Figure 4A) and two serous adenocaricoma implants on her left retroperitoneum (Figure 4B), and an intraepithelial carcinoma on inner surface of her right fallopian tube, near fimbriae (Figure 5).
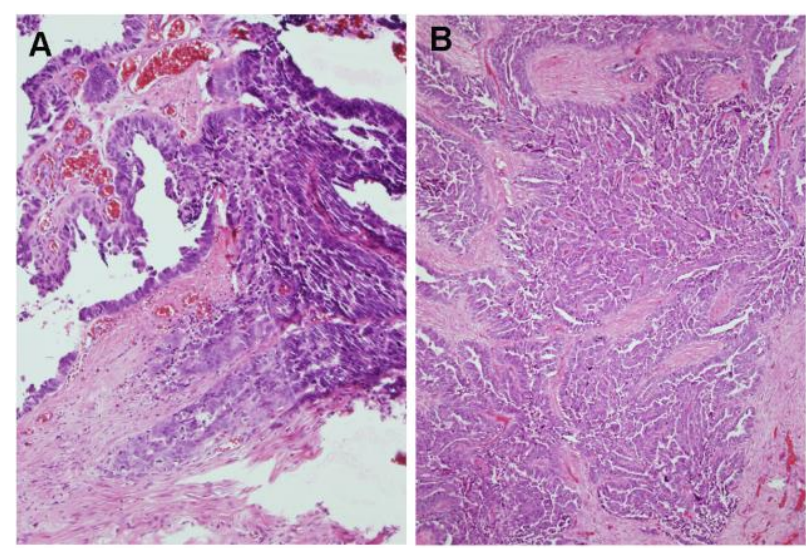

Figure 4: Microscopic findings of serous adenocarcinoma on left ovary (A) and on left retroperitoneum (B). Subepithelial invasion was seen in both specimens.

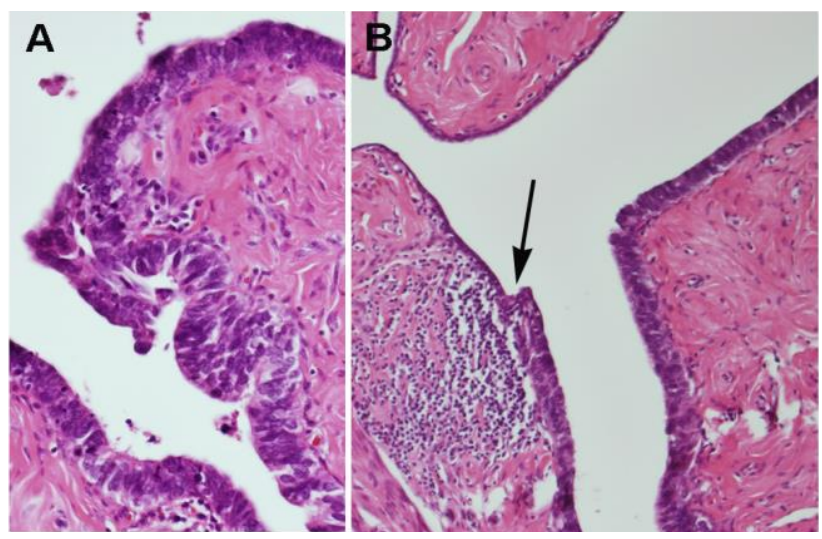

Figure 5: Microscopic findings of intra-epithelial carcinomas on inner surface of right Fallopian tube.

(A) Atypical and enlarged nuclei in epithelial cell layer. (B) Front formation between normal epithelium and intraepithelial carcinoma.

According to guideline of Japan Society of Gynecologic Oncology for stage II b ovarian cancer with serum CA25 serum level of $226 \mathrm{U} / \mathrm{mL}$, we recommended postoperative chemotherapy with paclitaxel and carboplatin to the patient. However, as the patient preferred not to undergo chemotherapy with strong side effects (e.g. hairloss), we scheduled carboplatin monotherapy. 
After the third course of chemotherapy, her serum CA125 level was $9 \mathrm{U} / \mathrm{mL}$ and the patient strongly hoped to finish the chemotherapy. Four months later, abdominal distension reappeared, and serum CA125 level was again elevated to $185 \mathrm{U} / \mathrm{mL}$. We diagnosed the cancer to have recurred within 6 months, and began third-line chemotherapy with liposomal doxorubicin. After 2 cycles of chemotherapy, her ascites disappeared and serum CA125 level was decreased to $89 \mathrm{U} / \mathrm{mL}$.

\section{DISCUSSION}

At the consensus meeting of the International Federation of Gynecology and Obstetrics (FIGO) in 2012, localized primary peritoneal cancer was classified as stage II. $^{2}$ In the present case, the primary ovarian cancer that was overlooked at macroscopic examination was found to be $<5 \mathrm{~mm}$ by pathologic examination, with the two peritoneal implants localized in pelvic cavity; the ovarian cancer was also stage II b.

As a small ovarian cancer may be overlooked, bilateral salpingo-oophorectomy is recommended in a patient with peritoneal cancer. In the absence of an obvious lesion, pathologic examination of ovary and fallopian tube specimens is important for accurate staging and evaluation.

Based on molecular genetics and morphologic studies, epithelial ovarian cancer is classified into two categories, type I, which include cancers with well-identified ovarian precursors, including low-grade serous carcinomas; and type II, which includes cancers with less-obvious precursors, including high-grade serous cancers. ${ }^{3,4}$ In up to $60 \%$ of cases with sporadic high-grade serous carcinoma of ovary, serous tubal intraepithelial carcinomas were found. ${ }^{5}$ Extensive evaluation protocols of fallopian tubes have shown the fimbriated end to be the most common site of serous tubal intraepithelial carcinoma. Their reports proposed that many serous ovarian cancers originate from tubal intraepithelial carcinoma, and the schema shows the carcinoma cells moving from the fimbriae to the same side ovary. ${ }^{6}$ Our case suggests that the carcinoma cells can move from a fimbria to the contralateral ovary.

\section{CONCLUSION}

Serous ovarian cancer could originate from an intraepithelial carcinoma of contralateral fallopian tube.

Funding: No funding sources

Conflict of interest: None declared

Ethical approval: Not required

\section{REFERENCES}

1. Eltabbakh GH, Piver MS. Extraovarian primary peritoneal carcinoma. Oncol. 1998;12(6);813-9.

2. Prat J. FIGO's staging classification for cancer of the ovary, fallopian tube, and peritoneum: abridged republication. J Gynecol Oncol. 2015;26(2):87-9.

3. Rojas V, Hirshfield KM, Ganesan S, RodriguezRodriguez L. Molecular characterization of epithelial ovarian cancer: implications for diagnosis and treatment. Int J Mol Sci. 2016;17(12):2113.

4. Dao F, Schlappe BA, Tseng J, Lester J, Nick A, Lutgendorf SK et al. Characterization of 10-year survivors of high-grade serous ovarian carcinoma. Gynecologic Oncol. 2016;141:260-3.

5. Zeppernick F, Meinhold-Heerlein I, Shih I-M Precursors of ovarian cancer in the fallopian tube: serous tubal intraepithelial carcinoma-an update. J Obstet Gynecol Res 2015;41(1):6-11.

6. George SHL, Garcia R, Slomovitz BM. Ovarian cancer: the fallopian tube as the site of origin and opportunities for prevention. Frontiers in Oncol. 2016;6:108.

Cite this article as: Terada $\mathrm{H}$, Honda $\mathrm{K}$, Nakagawa T, Takase A, Kurihara Y, Ando T. Unilateral minimal ovarian cancer with peritoneal implant and an intraepithelial carcinoma in the contralateral fallopian tube. Int J Reprod Contracept Obstet Gynecol 2017;6:1679-81. 